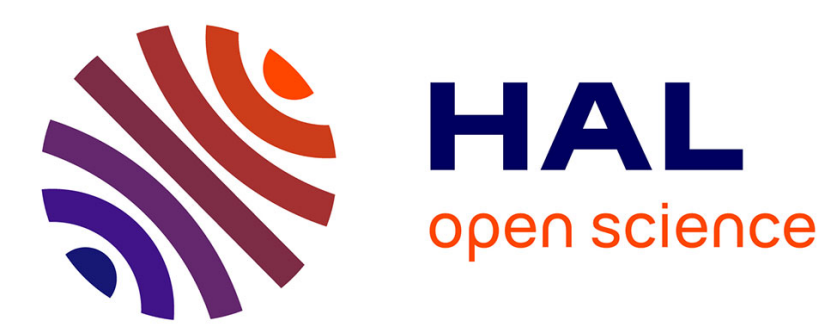

\title{
The Coactivator Activator CoAA regulates PEA3 group member transcriptional activity
}

Kathye Verreman, Jean-Luc Baert, Alexis Verger, Hervé Drobecq, Elisabeth Ferreira, Yvan de Launoit, Didier Monte

\section{- To cite this version:}

Kathye Verreman, Jean-Luc Baert, Alexis Verger, Hervé Drobecq, Elisabeth Ferreira, et al.. The Coactivator Activator CoAA regulates PEA3 group member transcriptional activity. Biochemical Journal, 2011, 439 (3), pp.469-477. 10.1042/BJ20110728 . hal-00633602

\section{HAL Id: hal-00633602 https://hal.science/hal-00633602}

Submitted on 19 Oct 2011

HAL is a multi-disciplinary open access archive for the deposit and dissemination of scientific research documents, whether they are published or not. The documents may come from teaching and research institutions in France or abroad, or from public or private research centers.
L'archive ouverte pluridisciplinaire HAL, est destinée au dépôt et à la diffusion de documents scientifiques de niveau recherche, publiés ou non, émanant des établissements d'enseignement et de recherche français ou étrangers, des laboratoires publics ou privés. 


\title{
The Coactivator Activator CoAA regulates PEA3 group member transcriptional activity.
}

\author{
Kathye VERREMAN ${ }^{1 \S}$, Jean-Luc BAERT ${ }^{2}$, Alexis VERGER $^{2}$, Hervé DROBECQ $^{1}$, \\ Elisabeth FERREIRA ${ }^{2}$, Yvan de LAUNOIT ${ }^{1}$ and Didier MONTE ${ }^{2 *}$
}

${ }^{1}$ UMR 8161, Institut de Biologie de Lille, CNRS / Université Lille Nord de France, Institut Pasteur de Lille, IFR 142, BP 447, 1 rue Calmette, 59021 Lille Cedex, France.

${ }^{2}$ Institut de Recherche Interdisciplinaire - IRI, USR 3078 CNRS - Université Lille Nord de France, Parc CNRS de la Haute Borne, 50 avenue de Halley - BP 70478 -59658 Villeneuve d'Ascq Cedex, France.

${ }^{\S}$ Present address : SBiGeM IBITEC, L-MARGE, Bâtiment 144, Commissariat à l'Energie Atomique de Saclay, 91191 Gif sur Yvette Cedex, France.

* Corresponding author: Didier MONTE

Phone: $33(0) 362531709$

Fax: $33(0) 362531701$

Email: didier.monte@,iri.univ-1ille1.fr

Short (page heading) title: CoAA regulates PEA3 group member transcriptional activity Keywords: ETS transcription factor, PEA3 group, CoAA, ERM, transcriptional regulation, RRM, migration

Abbreviations used:

CBP, CREB binding protein; CMV, Cytomegalovirus; CoAA, Coactivator activator; CoAM, Coactivator Modulator; DBD, DNA Binding Domain; E2F, E2 factor; ER81, ETS- 
related 81; ERM, ETS Related Molecule; ETS, E-twenty-six; EWS, Ewing's sarcoma protein ; GAPDH, Glyceraldehyde 3-phosphate dehydrogenase ; GHBP, Growth Hormonebinding protein; GST, glutathione S-transferase; hnRNP, heterogenous nuclear ribonucleoprotein; ICAM-1, Intracellular adhesion molecule 1; MMTV, mouse mammary tumor virus ; NIH-3T3, Mouse embryonic fibroblast cell line ; NP40, Nonidet P40; p54nrb, nuclear RNA-binding protein, $54 \mathrm{kDa}$; PEA3, Polyomavirus enhancer actiyator 3 ; RK13, Rabbit kidney cells ; RNP, Ribonucleoprotein Domain ; RRM, RNA recognition motifs ; RTPCR, Reverse Transcription PCR; SEM, standard error on the mean; siRNA, small interfering RNA; SWI/SNF, SWItch/Sucrose NonFermentable; SYT, synovial sarcoma translocation protein; TAD, Transactivation Domain; TLS/FUS ; Translocation/fusion in Liposarcoma; TK, Thymidine kinase; TRBP, Thyroid-hormone receptor binding protein ; USF1, Upstream Stimulatory Factor 1. 


\section{SYNOPSIS}

The PEA3 group members (ERM, ER81 and PEA3) of the Ets transcription factor family are involved in migration and dissemination processes during organogenesis and cancer development. In the present study, we report that the heterogeneous nuclear ribonucleoprotein (hnRNP)-like protein CoAA interacts with the PEA3 group members and modulates their transcriptional activity. We also demonstrate that the CoAA YQ domain, containing tyrosine/glutamine-rich hexapeptide repeats, is necessary for the interaction, whereas the two N-terminal RNA recognition motifs (RRM) of CoAA are required to enhance transcriptional activity. Finally, we show that CoAA is involved in the migrationenhancing action of PEA3 on MCF7 human cancer cells, suggesting that CoAA might be an important regulator of PEA3 group member activity during metastasis. 


\section{INTRODUCTION}

The Ets transcription factors share a DNA-binding domain (the ETS domain) of about 85 residues that binds the consensus core sequence 5'GGAA/T 3' (reviewed in [1]). On the basis of variations within this domain, different groups are distinguished [1]. The PEA3 group is composed of three highly conserved Ets transcription factors ERM, ER81, and PEA3. These factors are often overexpressed in cancers with a disseminating phenotype, and experimental modulation of their expression influences the invasive process, suggesting a key role of these factors in metastasis (reviewed in [2, 3]). For example, PEA3 expression is sufficient to confer invasive phenotype of human cancer cells MCF7 [4]. Moreover, PEA3 and ERM have been described as factors of poor prognosis in ovarian and breast tumors respectively $[5,6]$. PEA3 group members are prone to post-translational modifications, such as phosphorylation, acetylation, ubiquitinylation, and sumoylation [7-14] that regulate their transcriptional activity. Their activity is also regulated by interaction with protein partners such as Jun, USF-1 and CBP/p300 [13, 15, 16].

The Coactivator Activator (CoAA/RBM14) was originally reported as an activator of the coactivator TRBP (thyroid-hormone receptor binding protein) [17]. It was also isolated as a partner of a proto-oncogene, the synovial sarcoma translocation protein (SYT), a nuclear receptor coactivator known to bind to the SWI/SNF chromatin-remodeling complex $[18,19]$. Recently, Li et al. have shown that CoAA interacts with the RUNX2 DNA-binding domain, preventing RUNX2-driven gene expression [20]. CoAA is an hnRNP-like protein containing two N-terminal RNA recognition motifs (RRM) enabling it to act as a regulator of mRNA splicing [21-23]. The central YQ Domain of CoAA required for its interaction with TRBP, SYT, and RUNX2 possesses 27 tyrosine/glutamine-rich hexapeptide repeats and exhibits 
transcription-regulating activity $[17,18]$. Such a domain is also present in the oncoproteins EWS (Ewing's sarcoma), TLS/FUS (Translocation/Fusion in Liposarcoma), and SYT [18, 24]. CoAA is widely expressed in embryonic tissues, and its expression is prone to alternative splicing $[25,26]$. For example, splicing events can result in expression of the CoAM (Coactivator Modulator) splice variant. The balance between CoAA and CoAM isoforms has been clearly implicated in the regulation of early embryonic development [25, 26]. Furthermore, CoAA is overexpressed in a variety of cancers, its overexpression in NIH-3T3 cells increases cell proliferation and promotes colony formation in soft agar assays [24], while its knockdown blocks osteosarcoma cell growth in vitro [20]. Paradoxically, underexpression of CoAA transcripts is observed in certain cancers such as renal carcinoma. In renal carcinoma cells, it has recently been demonstrated that CoAA can act as a tumor suppressor by repressing expression of the c-Myc proto-oncogene [27]. CoAA can thus increase or decrease cell proliferation, depending on the cell model.

In this work we have used biotinylated ERM as bait to fish for new potential ERM partners in nuclear extracts and identified CoAA. We show that endogenous ERM and CoAA interact both in vitro and within cells and that CoAA modulates ERM transcriptional activity by interacting with ERM via its YQ domain. Interestingly, our results also indicate that the CoAA RRMs are required to enhance ERM activity. Similar effects are observed for the two other PEA3 group members, PEA3 and ER81. Moreover, we show that CoAA knockdown decreases ERM or PEA3-induced activation of ICAM-1. Finally, we demonstrate that in MCF7 human cancer cells, the PEA3 migratory activity is enhanced upon CoAA overexpression and decreased upon CoAA knockdown. 


\section{EXPERIMENTAL}

\section{Plasmid constructs}

The pSG5 expression vectors encoding full-length ERM, ER81, or PEA3 have been described elsewhere [12, 14, 28, 29]. The flag-tagged ERM vector (pSV flag-ERM) is described in [11]. The glutathione $S$-transferase (GST) fusion protein expression vectors have also been described previously [30, 31]. The vectors expressing flag-tagged-CoAA, -CoAM, or -AxxQ were kindly provided by Dr L. Ko (Medical College of Georgia, Institute of Molecular Medicine and Genetics, Augusta, USA) [17, 24]. The vectors expressing myctagged-CoAA, -CoAAC, -A1NCoAAC, or -hnRNPA1 were a gift from Dr D. Auboeuf (INSERM U685, Institut Universitaire d'Hématologie, Hôpital Saint-Louis, Paris, France) [22]. The pDelta-EndoA-Luc (EndoA-luciferase) plasmid carries a trimeric synthetic repeat of the Endo-A enhancer and was a generous gift from Dr Iniguez-Lluhi (University of Michigan Medical School, West Medical Center Dr Ann Arbor, USA) [32]. The ICAM1-Luc, CMV- $\beta$-galactosidase, E2F1-Luc, and 5xE2F-Luc reporter plasmids have been described previously $[14,28,33]$.

\section{Isolation of CoAA}

After washing in PBS, HeLa cells were lysed in hypotonic buffer (10 mM Hepes $\mathrm{KOH}$ pH 7.9, $10 \mathrm{mM} \mathrm{KCl}, 3 \mathrm{mM} \mathrm{MgCl2}, 1 \mathrm{mM}$ DTT, 0.1\% NP40, 1x complete protease inhibitor) for 5 min on ice. After centrifugation, the cytoplasmic supernatant was removed and the remaining nuclear pellet was resuspended in benzonase buffer $(20 \mathrm{mM}$ Hepes $\mathrm{pH} 8$, $150 \mathrm{mM} \mathrm{NaCl}, 3 \mathrm{mM} \mathrm{MgCl} 2,1 \mathrm{mM}$ DTT, 0.1\% NP40, 1x complete protease inhibitor (Roche)), after which benzonase digestion was performed for 2 hours at $16^{\circ} \mathrm{C}$. After centrifugation at $100,000 \mathrm{x}$ g for 1 hour at $4^{\circ} \mathrm{C}$, the supernatant was incubated for 2 hours at 
$4^{\circ} \mathrm{C}$ with biotinylated ERM 1-370 (produced in Escherichia coli and purified on streptavidincoupled beads - the detailed procedure is available upon request). The beads were then washed five times with benzonase buffer containing $250 \mathrm{mM} \mathrm{NaCl}$ and twice with benzonase buffer. The captured proteins were then eluted in Laemmli buffer, separated by SDS-PAGE, stained with Coomassie brilliant blue R-250, excised from the gel, and identified by mass spectrometry as previously described [34].

\section{In vitro protein-protein interaction}

$\left[{ }^{35} \mathrm{~S}\right]$ Methionine-labeled proteins were produced with the TNT T7 Quick Coupled Transcription-Translation System (Promega). The GST fusion proteins or GST alone bound to glutathione beads were incubated for $2 \mathrm{~h}$ at room temperature with the in vitro translated proteins in binding buffer containing $20 \mathrm{mM}$ Tris $\mathrm{HCl}$ (pH 7.4) $150 \mathrm{mM} \mathrm{NaCl}, 0.1 \%$ Triton, $40 \mu \mathrm{g} / \mathrm{ml} \mathrm{BSA}$, and $1 \mathrm{mM}$ DTT. After extensive washing with the same buffer, the bound proteins were analyzed by SDS-PAGE and revealed by autoradiography.

\section{Cell culture and transfection}

RK13 rabbit kidney cells, U2OS human osteosarcoma cells, HeLa human cervical cancer cells, MCF7 human breast cancer cells and HEK 293T human embryonic kidney cells were maintained in Dulbecco's Modified Eagle's Medium (DMEM) supplemented with 10\% heat-inactivated fetal calf serum (Gibco BRL) and grown at $37^{\circ} \mathrm{C}$ in a water-saturated $5 \%$ $\mathrm{CO}_{2}$ atmosphere. Transient transfections were performed by means of the PEI Exgen 500 procedure (Euromedex, France). Luciferase activity was determined $24 \mathrm{~h}$ after transfection and normalized with respect to the $\beta$-galactosidase activity (used as an internal control of 
transfection efficiency) as previously described [11]. The data presented are means \pm SEM of at least three independent experiments. SiRNA SMART pool (Dharmacon) was used to knock down CoAA in the cells. Interferin (Polyplus-transfection) was used according to the manufacturer's protocol to transfect cells with siRNA.

\section{Immunoprecipitation and western blot analyses}

U2OS cells were lysed in co-immunoprecipitation buffer $(50 \mathrm{mM}$ Tris/ $\mathrm{HCl}, \mathrm{pH} 7.5$, $125 \mathrm{mM} \mathrm{NaCl}, 0.2 \mathrm{mM}$ EDTA, $1 \mathrm{mM}$ DTT, and $0.5 \%$ Triton X100) with $1 \mathrm{x}$ complete protease inhibitor, and the cell extract was centrifuged at $100,000 \times \mathrm{g}$ for $30 \mathrm{~min}$ at $4^{\circ} \mathrm{C}$. The supernatant was immunoprecipitated overnight with anti-ERM antibody (anti-ERM $355-510$ ) $[12,14,28,29]$ or pre-immune serum and then incubated with protein A-Sepharose beads for an additional $1 \mathrm{~h}$ at $4^{\circ} \mathrm{C}$. After washing with lysis buffer, the immunopurified proteins were eluted with Laemmli sample buffer. Immunopurified proteins and total cell extracts were analyzed by SDS-PAGE and then electrophoretically transferred to nitrocellulose membranes. Immunoblot analyses were performed with rabbit anti-ERM antibody (anti-ERM $12-226$, which cross-reacts with both other PEA3 group members [30]), anti-CoAA (Bethyl), anti-flag (Sigma), anti-myc (Sigma), or anti-actin antibody (sc1616, Santa Cruz Biotechnology). This was followed by treatment with horseradish-peroxidase-conjugated secondary antibody or horseradish-peroxidase-conjugated anti-rabbit Immunoglobulin G TrueBlot (eBioscience). Immune complexes were visualized by enhanced chemiluminescence according to the manufacturer's instructions (Santa Cruz Biotechnology). Prestained broad-range molecular weight markers (New England BioLabs) were used as standards in each SDS-PAGE.

\section{Reverse transcription PCR (RT-PCR)}


TRI Reagent (Molecular Research Center, Inc) was used as described by the manufacturer to isolate RNA from control or CoAA-downregulated HeLa cells transfected with 200 ng pSG5 ERM. The corresponding cDNAs were synthesized with the High Archive cDNA kit (Applied Biosystems). Quantitative PCR was performed with the brilliant SYBRgreen qPCR master mix (Stratagene) in an MX3005P instrument as described by the supplier, with the following specific primers: GAPDH (sense 5'AAGGTGGTGAAGCAGGCGT-3' and antisense 5'-AGGTCCACCACCCTGTTGC-3'); ICAM1 (sense 5'-GCCAGGAGACACTGCAGACA-3' and antisense 5'TGGCTTCGTCAGAATCACGTT-3’').

\section{In vitro migration assay}

The in vitro migration assay was performed by using a modified Boyden chamber inserted with a membrane containing $8 \mu \mathrm{m}$ pores in 24 -well plates (BD). MCF7 cells were transfected with plasmids using Fugene HD (Roche) and/or retransfected 6 hours later with siRNA using Interferin (Poly-Plus). After 24 hours, cells were trypsinized and resuspended in culture medium. A total of $2 \times 10^{5}$ or $5 \times 10^{5}$ cells were added to the upper compartment of the transwell chamber. The lower chamber was filled with medium. 24 hours later, the cells were fixed with $4 \%$ paraformaldehyde and stained with $0.5 \%$ crystal violet. The cells remaining on the upper surface of the filter membrane were then completely removed by wiping with a cotton swab. For each well, the migrated cells were visualised and counted from three randomly selected fields under an inverted microscope. Migration assay was also performed in the presence of mitomycin $\mathrm{C}(3 \mu \mathrm{g} / \mathrm{ml})$ to inhibit cell proliferation (Figures $6 \mathrm{~A}$ and $6 \mathrm{~B})$. 


\section{RESULTS}

\section{ERM and CoAA interact in vitro and in vivo}

In an attempt to isolate new nuclear proteins that might functionally modulate ERM transcriptional activity, we used a biotin-tagged ERM fragment (1-370) or the biotinylated tag alone (control) immobilized on streptavidin beads as bait (Figure 1A). ERM-bound nuclear proteins were then identified by mass spectrometry. Purification of ERM partners was performed four times. Among the ERM-bound nuclear proteins, we reproducibly identified CBP (band 1, Fig. 1A), a known partner of the PEA3 group members $[13,15,16]$, and the transcriptional Coactivator Activator (CoAA: band 2, Fig. 1A). We thus decided to further investigate whether CoAA modulates ERM activity.

To confirm the direct interaction between ERM and CoAA, we first performed a GST pull-down assay with GST-ERM and in vitro-translated $\left[{ }^{35} \mathrm{~S}\right]$ methionine-labeled CoAA. As shown in Figure 1B, radiolabeled CoAA interacted strongly with GST-ERM as compared to GST alone. To determine whether ERM associates with CoAA in vivo, extracts of U2OS human osteosarcoma cells were immunoprecipitated with anti-ERM antibodies and then western blotting was performed with CoAA- and ERM-specific antibodies. As shown in Fig. 1C, a significant amount of endogenous CoAA co-precipitated with anti-ERM but not with pre-immune serum, suggesting that ERM associates with CoAA in the cell.

As the three PEA3 group members present a high sequence homology, the in vitro study was extended to the other PEA3 group members, ER81 and PEA3. Like ERM, these transcription factors were found to interact strongly with GST-CoAA in GST pull-down 
experiments (Figure 1D). These results clearly identify CoAA as a binding partner for the PEA3 group members.

\section{Mapping of the CoAA-ERM interaction domains}

To narrow down the CoAA and ERM regions necessary for the interaction of these proteins, we performed GST pull-down experiments with different mutant and deletion constructs.

We first used (Figure 2A, left panel) the natural CoAA splice variant CoAM, containing only the two N-terminal RRM domains, and an N-terminal deletion mutant lacking these domains (CoAAC). CoAM was found to interact very poorly, and CoAAC strongly, with GST-ERM (Figure 2A, right panel), suggesting that the C-terminal part of CoAA containing the YQ domain is mainly responsible for ERM-CoAA interaction. We then tested the AxxQ mutant, where all the tyrosine residues of the YQ domain have been replaced with alanines [24]. This mutant was unable to bind GST-ERM, further indicating that the ERM-CoAA interaction depends on the YQ domain. Similar results were observed for PEA3 and ER81 (data not shown).

We next mapped the CoAA-interacting domain of ERM. ERM shares a similar architecture with the two other PEA3 group members: an N-terminal transactivation domain and the ETS DNA-binding domain located on the C-extremity (Figure $2 \mathrm{~B}$, left panel). As shown in Figure 2B, CoAA interacted strongly with $\mathrm{ERM}_{1-510}$ and $\mathrm{ERM}_{1-370}$ but not with ERM $_{354-510}$, indicating that the ETS DNA-binding domain and the C-terminal part of ERM are totally dispensable for ERM-CoAA interaction. Further ERM C-terminal deletions progressively decreased CoAA interaction (Figure 2C, compare $\mathrm{ERM}_{1-370}, \mathrm{ERM}_{1-298}$, and $\mathrm{ERM}_{1-226}$ ), indicating that residues 226-370 of ERM are important for CoAA recruitment. 
Similar results were obtained with progressive ERM N-terminal deletion constructs (Figure 2C, compare $\mathrm{ERM}_{1-510}, \mathrm{ERM}_{112-510}$ and $\mathrm{ERM}_{203-510}$ ). Taken together, these results suggest that the ERM region between residues 112 and 298 is necessary for optimal interaction with the YQ domain of CoAA.

\section{CoAA overexpression increases the PEA3 group member transcriptional activity}

We next assessed the effect of CoAA on PEA3 group member transcriptional activity. Luciferase reporter gene assays were first performed with ERM and the EndoA-Luc reporter plasmid. As shown in Figure 3A, CoAA did not significantly increase the basal EndoA enhancer activity. It did, however, increase ERM-induced EndoA enhancer activity in a dosedependent manner. In contrast, the AxxQ mutant (unable to bind ERM) had no effect. This indicates that direct interaction between CoAA and ERM is necessary to promote the transcription-increasing effect of CoAA. The CoAA effect cannot be explained by a change in the ERM protein level, since neither CoAA nor AxxQ expression had any significant effect on this level in transfected RK13 cells (Figure 3A, right panel).

We also performed experiments with an ICAM-1-luciferase reporter construct. As observed for EndoA, CoAA, but not AxxQ, increased ERM-induced transcription of the ICAM-1 promoter (Figure 3B). The YQ domain of CoAA appears thus essential to potentiate ERM-dependent transcription from different ETS-responsive reporter constructs. CoAA is unable, however, to stimulate E2F transcription factor activity (Figure 3C), suggesting that it does not act as a general transcription factor activator.

We next assessed whether CoAA could also affect the transcriptional activity of ER81 and PEA3. As shown in Figure 3D, the transcription-activating action of PEA3 and ER81 on the EndoA-Luc reporter construct was clearly stimulated by CoAA but not by AxxQ. Similar results were also observed with the ICAM-1 reporter construct (data not shown). Taken 
together, these results suggest that CoAA regulates the activity of ERM, PEA3, and ER81 through a similar pathway.

\section{CoAA RRMs are required for CoAA-mediated activation of ERM activity}

As the RRMs of CoAA are not required for CoAA-ERM interaction, we next investigated whether they are necessary for CoAA-dependent activation of ERM. Luciferase reporter gene assays were performed with CoAAC (CoAA without its RRMs). In contrast to CoAA, this deletion mutant was unable to stimulate ERM-induced transcription of the EndoA-Luc reporter construct (Figure 4A), although its level of production was similar (Figure 4A) and although it still interacted with ERM (Figure 4B). This suggests that the interaction with ERM is not sufficient to induce transcriptional activation and that the RRMs are required in this process. The RRM domains share a conserved structure containing two short conserved sequences called RNP-1 and RNP-2 (ribonucleoprotein domains 1 and 2), forming a four-stranded $\beta$-sheet backed by two $\alpha$-helices [35]. Interestingly, CoAA shares a similar architecture with two other hnRNP-related proteins, p54nrb and hnRNPA1: two Nterminal RRMs followed by an auxiliary domain. Furthermore, the RRMs of both hnRNPA1 and p54nrb can partially replace the CoAA RRMs of CoAA in mediating some of the transcriptional effects of CoAA [22]. We thus evaluated the effect of the RRMs of CoAA on ERM by replacing them with the related RRMs of hnRNPA1. As shown in Figure 4B, A1NCoAAC (CoAA with the RRMs hnRNPA1), in contrast to hnRNPA1, was found to interact with ERM, confirming that the YQ domain is sufficient to recruit ERM. Like hnRNPA1, however, A1N-CoAAC was unable to stimulate ERM-induced transcription of the EndoA reporter construct (Figure 4A). Similar results were obtained with the N-terminal RRMs of p54nrb (data not shown). Taken together, our results indicate that the RRMs of CoAA are 
required to mediate the effect of CoAA on ERM transcriptional activity, even though they are not required for CoAA-ERM interaction.

\section{CoAA knockdown decreases ERM transcriptional activity.}

We then carried out RNA interference experiments to determine the effect of CoAA knockdown on ERM transcriptional activity. Two days after transfection of HeLa cells with the CoAA siRNA, the CoAA protein level was clearly diminished (Figure 5A). We then used qPCR to estimate, in HeLa cells overexpressing ERM, the effect of CoAA knockdown on transcription of the endogenous ICAM-1 gene (an ERM target gene [28]) (Figure 5B). In the absence of ERM, the ICAM-1 mRNA level was found to increase slightly but significantly in response to knockdown of endogenous CoAA. As predicted, a major increase in this level was observed when ERM was expressed. CoAA knockdown, however, was found to reduce the level of ICAM-1 mRNA observed in the presence of overexpressed ERM (Figure 5B). Similarly, siRNA knockdown of endogenous CoAA causes a decrease in PEA3-dependent transcription of the ICAM-1 promoter (data not shown). This suggests that endogenous CoAA is involved in the regulation of the PEA3 group member transcriptional activity.

\section{CoAA participates to the PEA3 migratory activity on the human cancer cells MCF7}

Since PEA3 has been reported to stimulate the migration of MCF7 cells [4], we examined whether CoAA could be implicated in this process. One day after transfection of MCF7 cells with CoAA and/or PEA3 plasmid, CoAA and PEA3-triggered migration was examined using the Transwell assay in the presence of mitomycin $\mathrm{C}$ to eliminate the contribution of cell proliferation. As expected, PEA3 overexpression induces significant motility of MCF7 cells (Figure 6A and B). Interestingly, cell migration in the presence of 
both CoAA and PEA3 was more than the sum of the effects of CoAA or PEA3 alone, suggesting a synergistic effect. This synergy was not observed between PEA3 and AxxQ (data not shown).

To assess the effect of the depletion of CoAA on the PEA3-induced migratory activity, we carried out similar experiments by transfecting MCF7 cells with siRNA directed against CoAA (siRNA CoAA, Figure 6C and D). When combined with PEA3 overexpression, siRNA CoAA appears to counteract the migration-enhancing action of PEA3. Taken together, these results suggest that CoAA is important for the effects of PEA3 on cell migration.

\section{DISCUSSION}

In the present study we have identified the Coactivator Activator (CoAA) as a new ERM partner and extended the in vitro interaction to the two other PEA3 group members, PEA3 and ER81. Moreover we show that ERM interacts with CoAA in living cells and that the CoAA domain involved in this interaction is the YQ Domain. Five CoAA interactors have been identified previously: the coactivator TRBP and the histone acetyltransferase CREB binding protein (CBP) [17], the proto-oncogene coactivator SYT [18, 19], the extracellular domain of the GH receptor called the GH-binding protein (GHBP) [36] and the transcription factor RUNX2 [20]. While the domain of CoAA involved in the interaction with GHBP and CBP remains to be determined, the other three partners are known to require the YQ domain $[17,18,20]$. This domain contains more than 20 XYXXQ motifs (X denotes a small amino acid residue, i.e. G, A, S, or P) [17] and exhibits transcriptional activity [18]. Previous studies have shown that the aromatic residue repeats interspersed among the small residues are 
important for allowing protein-protein interactions $[17,19,37,38]$. Our work confirms that this motif plays a crucial role in such interactions and particularly highlights the central role of the tyrosine residues, since their replacement with alanines abolishes the interaction with the PEA3 group members. The YQ domain is also present in the EWS, TLS/FUS (translocation/fusion in liposarcoma) and SYT [18, 24] oncoproteins, and it would be interesting to test whether it allows the interaction of these proteins with PEA3 group members, as seen with RUNX2, which interacts with CoAA, TLS/FUS and EWS [39].

The interaction domains defined in the known CoAA partners are relatively large regions: the SYT C-terminal transactivating domain (QPGY domain, AA 73-387) [18], the C terminus (AA 1641-2063) and the LXXLL-containing region (AA 719-999) of TRBP [17], the DNA binding domain of RUNX2 (AA 50-179) [20], and the C-terminal region (AA 11952414) of p300/CBP [17]. Remarkably, no sequence homology is observed between these domains. The integrity of ERM central region (AA 112-298) appears necessary for optimal interaction with CoAA. This region shows no significant homology with the interaction domains of the other CoAA partners. Interestingly, as observed with the SYT QPGY domain [18] and the TRBP domain [17], the 112-298 region of all three PEA3 group members are proline-rich (proline content: about 15\%). As previous studies have shown that proline-rich regions are important for protein-protein interactions [40, 41], a proline-rich region might be one of the features necessary for CoAA binding to interacting domains.

We further show that CoAA increases the transcription-enhancing action of PEA3 group members of the EndoA and ICAM-1 promoters in RK13 cells. This activating function was also observed in human cells (such as HeLa and U2OS cells, data not shown). While CoAA can upregulate the basal transcription of MMTV- and CMV-luciferase reporter genes in HeLa cells [22], it appears not to significantly increase basal EndoA- or ICAM-1- 
promoter-driven transcription. Consistent with its role as a coactivator, siRNA knockdown of endogenous CoAA causes a decrease in PEA3 group member-dependent transcription. CoAA siRNA was also found to increase the basal expression of ICAM-1 in the absence of PEA3 group member expression, suggesting that CoAA may regulate the expression of ICAM-1 in HeLa cells via an additional mechanism that does not require CoAA-PEA3 group members binding.

To date, the activating function of CoAA has been observed with the coactivators SYT, CBP, TRBP, and GHBP $[17-19,36]$. On the other hand, CoAA interaction with the DNA-binding domain of RUNX2 has been found to decrease RUNX2 binding to its target gene [20]. As RUNX2 can act as a repressor or an activator, its interaction with CoAA can increase or decrease the expression of its target genes. However, CoAA does not interact with the ERM DNA-binding domain. Furthermore, we have observed enhancement by CoAA of the transcriptional activity of an ERM construct in which the ETS domain was replaced with the Gal4 DNA-binding domain (data not shown). This strongly suggests that CoAAdependent PEA3 group member activation does not depend on the DNA-binding process. Moreover, CoAA stimulates PEA3 group member transcriptional activity without affecting significantly their level or cellular localization (data not shown). It thus likely modulates PEA3 group member transcriptional activity by recruiting coactivators, preventing interaction with corepressors, or modulating PEA3 group member post-translational modifications. Further work will be required to determine which of these mechanisms are involved.

CoAA is an hnRNP-like protein with two N-terminal RRMs. It is involved in promoter-specific mRNA splicing as well as transcriptional activation [21-23]. As the luciferase reporter constructs used in our experiments have no introns, the present experiments could teach us nothing about CoAA splicing effects. As deletion or substitution 
of the CoAA RRM domains can completely abolish the stimulation of ERM transcriptional activity by CoAA without affecting the later's binding to ERM, direct interaction between CoAA and ERM appears insufficient to promote the ERM-activating effect of CoAA. Furthermore, our results emphasize the importance and specificity of the COAA N-terminal RRMs in this process. Interestingly, similar deletion of the CoAA RRMs affects the response of MMTV reporter constructs to dexamethasone treatment [17]. Moreover, Auboeuf et al. have demonstrated that the RRMs of CoAA are necessary for transcription from CMV reporter constructs [22]. The functional role of the RRMs in CoAA-mediated enhancement of ERM transcriptional activity leads us to suppose that they are necessary for contact with coactivators or regulatory complexes. These coactivators are probably neither SYT nor TRBP, since they bind directly to the YQ domain. In support of this hypothesis, CoAAC (which contains the YQ domain and can still interact with ERM) causes dose-dependent inhibition of ERM transcriptional activity (data not shown), probably by competing with endogenous CoAA.

In terms of functional effect, our results demonstrate that the co-expression of CoAA and PEA3 triggers an important increase of MCF7 migration and that CoAA knockdown counteracts the PEA3-induced migratory activity. The PEA3 group members are well known to act as positive regulators of the expression of genes associated with proliferation, transformation, migration and invasion [2]. The enhancement of the migratory effect of PEA3 mediated by CoAA must probably be correlated to the increase of PEA3 target genes. Taken together, our results point out that CoAA may be an important regulator of PEA3 group member activity during metastasis. 


\section{ACKNOWLEDGMENTS}

We thank L. Ko, JA. Iniguez-Lluhi, S. Berger and D. Auboeuf for kind gifts of plasmids. We thank F. Leteurtre and T. Lejeune for technical help.

\section{FUNDINGS}

This work was carried out thanks to grants awarded by the «Ligue Nationale Contre le Cancer» (Comité Nord, France), the «Conseil Régional Nord/Pas-de-Calais » (France), the Fondation pour la Recherche Médicale (France), the Association pour la Recherche sur le Cancer (ARC; France), and the European Regional Development Fund (Intergenes program). K. V. was supported by fellowships from the Institut Pasteur de Lille/Région Nord-Pas de Calais and from the ARC.

\section{REFERENCES}

1 Graves, B. J. and Petersen, J. M. (1998) Specificity within the ets family of transcription factors. Adv Cancer Res. 75, 1-55

2 de Launoit, Y., Baert, J. L., Chotteau-Lelievre, A., Monte, D., Coutte, L., Mauen, S., Firlej, V., Degerny, C. and Verreman, K. (2006) The Ets transcription factors of the PEA3 group: transcriptional regulators in metastasis. Biochim Biophys Acta. 1766, 79-87

3 Kurpios, N. A., Sabolic, N. A., Shepherd, T. G., Fidalgo, G. M. and Hassell, J. A. (2003) Function of PEA3 Ets transcription factors in mammary gland development and oncogenesis. J Mammary Gland Biol Neoplasia. 8, 177-190

4 Kaya, M., Yoshida, K., Higashino, F., Mitaka, T., Ishii, S. and Fujinaga, K. (1996) A single ets-related transcription factor, E1AF, confers invasive phenotype on human cancer cells. Oncogene. 12, 221-227

5 Davidson, B., Goldberg, I., Gotlieb, W. H., Kopolovic, J., Ben-Baruch, G. and Reich, R. (2003) PEA3 is the second Ets family transcription factor involved in tumor progression in ovarian carcinoma. Clin Cancer Res. 9, 1412-1419 
6 Chotteau-Lelievre, A., Revillion, F., Lhotellier, V., Hornez, L., Desbiens, X., Cabaret, V., de Launoit, Y. and Peyrat, J. P. (2004) Prognostic value of ERM gene expression in human primary breast cancers. Clin Cancer Res. 10, 7297-7303

7 Baert, J. L., Beaudoin, C., Monte, D., Degerny, C., Mauen, S. and de Launoit, Y. (2007) The 26S proteasome system degrades the ERM transcription factor and regulates its transcription-enhancing activity. Oncogene. 26, 415-424

8 Guo, B. and Sharrocks, A. D. (2009) Extracellular signal-regulated kinase mitogenactivated protein kinase signaling initiates a dynamic interplay between sumoylation and ubiquitination to regulate the activity of the transcriptional activator PEA3. Mol Cell Biol. 29, 3204-3218

9 Degerny, C., de Launoit, Y. and Baert, J. L. (2008) ERM transcription factor contains an inhibitory domain which functions in sumoylation-dependent manner. Biochim Biophys Acta. 1779, 183-194

10 Bojovic, B. B. and Hassell, J. A. (2008) The transactivation function of the Pea3 subfamily Ets transcription factors is regulated by sumoylation. DNA Cell Biol. 27, 289-305

11 Degerny, C., Monte, D., Beaudoin, C., Jaffray, E., Portois, L., Hay, R. T., de Launoit, Y. and Baert, J. L. (2005) SUMO modification of the Ets-related transcription factor ERM inhibits its transcriptional activity. J Biol Chem. 280, 24330-24338

12 Janknecht, R., Monte, D., Baert, J. L. and de Launoit, Y. (1996) The ETS-related transcription factor ERM is a nuclear target of signaling cascades involving MAPK and PKA. Oncogene. 13, 1745-1754

13 Goel, A. and Janknecht, R. (2003) Acetylation-mediated transcriptional activation of the ETS protein ER81 by p300, P/CAF, and HER2/Neu. Mol Cell Biol. 23, 6243-6254

14 Baert, J. L., Beaudoin, C., Coutte, L. and de Launoit, Y. (2002) ERM transactivation is up-regulated by the repression of DNA binding after the PKA phosphorylation of a consensus site at the edge of the ETS domain. J Biol Chem. 277, 1002-1012

15 Nakae, K., Nakajima, K., Inazawa, J., Kitaoka, T. and Hirano, T. (1995) ERM, a PEA3 subfamily of Ets transcription factors, can cooperate with c-Jun. J Biol Chem. 270, 23795-23800

16 Firlej, V., Bocquet, B., Desbiens, X., de Launoit, Y. and Chotteau-Lelievre, A. (2005) Pea3 transcription factor cooperates with USF-1 in regulation of the murine bax transcription without binding to an Ets-binding site. J Biol Chem. 280, 887-898

17 Iwasaki, T., Chin, W. W. and Ko, L. (2001) Identification and characterization of RRM-containing coactivator activator (CoAA) as TRBP-interacting protein, and its splice variant as a coactivator modulator (CoAM). J Biol Chem. 276, 33375-33383

18 Perani, M., Antonson, P., Hamoudi, R., Ingram, C. J., Cooper, C. S., Garrett, M. D. and Goodwin, G. H. (2005) The proto-oncoprotein SYT interacts with SYT-interacting protein/co-activator activator (SIP/CoAA), a human nuclear receptor co-activator with similarity to EWS and TLS/FUS family of proteins. J Biol Chem. 280, 42863-42876

19 Iwasaki, T., Koibuchi, N. and Chin, W. W. (2005) Synovial sarcoma translocation (SYT) encodes a nuclear receptor coactivator. Endocrinology. 146, 3892-3999

20 Li, X., Hoeppner, L. H., Jensen, E. D., Gopalakrishnan, R. and Westendorf, J. J. (2009) Co-activator activator (CoAA) prevents the transcriptional activity of Runt domain transcription factors. J Cell Biochem. 108, 378-387

21 Auboeuf, D., Dowhan, D. H., Kang, Y. K., Larkin, K., Lee, J. W., Berget, S. M. and O'Malley, B. W. (2004) Differential recruitment of nuclear receptor coactivators may determine alternative RNA splice site choice in target genes. Proc Natl Acad Sci U S A. 101, $2270-2274$ 
22 Auboeuf, D., Dowhan, D. H., Li, X., Larkin, K., Ko, L., Berget, S. M. and O'Malley, B. W. (2004) CoAA, a nuclear receptor coactivator protein at the interface of transcriptional coactivation and RNA splicing. Mol Cell Biol. 24, 442-453

23 Auboeuf, D., Dowhan, D. H., Dutertre, M., Martin, N., Berget, S. M. and O'Malley, B. W. (2005) A subset of nuclear receptor coregulators act as coupling proteins during synthesis and maturation of RNA transcripts. Mol Cell Biol. 25, 5307-5316

24 Sui, Y., Yang, Z., Xiong, S., Zhang, L., Blanchard, K. L., Peiper, S. C., Dynan, W. S., Tuan, D. and Ko, L. (2007) Gene amplification and associated loss of 5' regulatory sequences of CoAA in human cancers. Oncogene. 26, 822-835

25 Yang, Z., Sui, Y., Xiong, S., Liour, S. S., Phillips, A. C. and Ko, L. (2007) Switched alternative splicing of oncogene CoAA during embryonal carcinoma stem cell differentiation. Nucleic Acids Res. 35, 1919-1932

26 Brooks, Y. S., Wang, G., Yang, Z., Smith, K. K., Bieberich, E. and Ko, L. (2009) Functional pre- mRNA trans-splicing of coactivator CoAA and corepressor RBM4 during stem/progenitor cell differentiation. J Biol Chem. 284, 18033-18046

27 Kang, Y. K., Schiff, R., Ko, L., Wang, T., Tsai, S. Y., Tsai, M. J. and O'Malley, B. W. (2008) Dual roles for coactivator activator and its counterbalancing isoform coactivator modulator in human kidney cell tumorigenesis. Cancer Res. 68, 7887-7896

28 de Launoit, Y., Audette, M., Pelczar, H., Plaza, S. and Baert, J. L. (1998) The transcription of the intercellular adhesion molecule-1 is regulated by Ets transcription factors. Oncogene. 16, 2065-2073

29 Coutte, L., Monte, D., Baert, J. L. and de Launoit, Y. (1999) Genomic organization of the human elaf gene, a member of Ets transcription factors. Gene. 240, 201-207

30 Baert, J. L., Monte, D., Musgrove, E. A., Albagli, O., Sutherland, R. L. and de Launoit, Y. (1997) Expression of the PEA3 group of ETS-related transcription factors in human breast-cancer cells. Int. J. Cancer. 70, 590-597

31 Laget, M. P., Defossez, P. A., Albagli, O., Baert, J. L., Dewitte, F., Stéhelin, D. and de Launoit, Y. (1996) Two functionally distinct domains responsible for transactivation by the Ets family member ERM. Oncogene. 12, 1325-1336

32 Iniguez-Lluhi, J. A. and Pearce, D. (2000) A common motif within the negative regulatory regions of multiple factors inhibits their transcriptional synergy. Mol Cell Biol. 20, 6040-6050

33 Blais, A., Monté, D., Pouliot, F. and Labrie, C. (2002) Regulation of the human cyclin-dependent kinase inhibitor p18INK4c by the transcription factors E2F1 and Sp1. J Biol Chem. 277, 31679-31693

34 Rocha-Perugini, V., Montpellier, C., Delgrange, D., Wychowski, C., Helle, F., Pillez, A., Drobecq, H., Le Naour, F., Charrin, S., Levy, S., Rubinstein, E., Dubuisson, J. and Cocquerel, L. (2008) The CD81 partner EWI-2wint inhibits hepatitis C virus entry. PLoS One. 3, e1866

35 Maris, C., Dominguez, C. and Allain, F. H. (2005) The RNA recognition motif, a plastic RNA-binding platform to regulate post-transcriptional gene expression. Febs J. 272, 2118-2131

36 Conway-Campbell, B. L., Brooks, A. J., Robinson, P. J., Perani, M. and Waters, M. J. (2008) The extracellular domain of the growth hormone receptor interacts with coactivator activator to promote cell proliferation. Mol Endocrinol. 22, 2190-2202

37 Cartegni, L., Maconi, M., Morandi, E., Cobianchi, F., Riva, S. and Biamonti, G. (1996) hnRNP A1 selectively interacts through its Gly-rich domain with different RNAbinding proteins. J Mol Biol. 259, 337-348 
38 Biamonti, G., Ruggiu, M., Saccone, S., Della Valle, G. and Riva, S. (1994) Two homologous genes, originated by duplication, encode the human hnRNP proteins A2 and A1. Nucleic Acids Res. 22, 1996-2002

39 Li, X., Decker, M. and Westendorf, J. J. (2010) TEThered to Runx: novel binding partners for runx factors. Blood Cells Mol Dis. 45, 82-85

40 Solheim, S. A., Torgersen, K. M., Tasken, K. and Berge, T. (2008) Regulation of FynT function by dual domain docking on PAG/Cbp. J Biol Chem. 283, 2773-2783

41 Kay, B. K., Williamson, M. P. and Sudol, M. (2000) The importance of being proline: the interaction of proline-rich motifs in signaling proteins with their cognate domains. FASEB J. 14, 231-241 


\section{FIGURE LEGENDS}

\section{FIGURE 1. ERM AND COAA INTERACT IN VITRO AND IN VIVO}

(A) Isolation of CoAA. HeLa-cell nuclear extract was incubated for 2 hours at $4^{\circ} \mathrm{C}$ with biotinylated ERM 1-370 (biotin tagged ERM) or biotinylated tag (control) purified on streptavidin-coupled beads. After extensive washing, the captured proteins were eluted in Laemmli buffer, separated by SDS-PAGE, stained with Coomassie, and identified by mass spectrometry. 1: CBP; 2: CoAA. (B) In vitro-translated $\left[{ }^{35} \mathrm{~S}\right]$ methionine-labeled CoAA was incubated with GST or GST-ERM. $10 \%$ of the amount of in vitro-translated $\left[{ }^{35} \mathrm{~S}\right]$ methioninelabeled CoAA used is shown as Input. (C) Co-immunoprecipitation of endogenous ERM and CoAA from U2OS cells. Immunoprecipitation was performed with anti-ERM antibody or preimmune serum (Pre) and proteins were detected as indicated with ERM- and CoAAspecific antibodies. The asterisk denotes a nonspecific band. (D) In vitro-translated $\left[{ }^{35} \mathrm{~S}\right]$ methionine-labeled ERM, PEA3, or ER81 was incubated with GST or GST-CoAA. Input: $10 \%$ of the amount of in vitro-translated $\left[{ }^{35} \mathrm{~S}\right]$ methionine-labeled protein used in the reaction.

\section{Figure 2. Mapping of the CoAA-ERM interaction domains}

(A) Left panel: Schematic representation of CoAA and the mutants used in this study. RRM: RNA recognition motifs, YQ domain: tyrosine/glutamine-rich domain. Right panel: In vitrotranslated $\left[{ }^{35} \mathrm{~S}\right]$ methionine-labeled CoAA, CoAAC, CoAM, or AxxQ was incubated with GST or GST-ERM. $20 \%$ of the amount of in vitro-translated $\left[{ }^{35} \mathrm{~S}\right]$ methionine-labeled proteins used is shown as Input. (B) Left panel: Schematic representation of ERM and the deletion mutants used in this study. TAD: N-terminal transactivation domain, ETS: DNAbinding domain. Right upper panel: autoradiography of in vitro-translated $\left[{ }^{35} \mathrm{~S}\right]$ methioninelabeled CoAA incubated with GST, GST-ERM (GST 1-510), GST 1-370, or GST 354-510. 
$20 \%$ of the in vitro-translated CoAA used is shown as Input. Right bottom panel: Coomassie staining of the GST-tagged proteins used in the upper panel. (C) Left panel: Schematic representation of ERM and the deletion mutants used in this study. Right upper panel: autoradiography of in vitro-translated $\left[{ }^{35} \mathrm{~S}\right]$ methionine-labeled CoAA after incubation with GST, GST-ERM, or GST fused to the various N- or C-terminal deletion mutants described in the left panel. Right bottom panel: Coomassie staining of the GST-tagged proteins used in the upper panel.

\section{FIGURE 3. CoAA increases the PEA3 group member transcriptional activity}

(A) Left panel: RK13 cells were transfected without (ctrl) or with ERM and an increasing quantity of CoAA (from 2.5 to $20 \mathrm{ng}$ Flag-CoAA plasmid) together with the EndoA-Luc reporter plasmid, $*=$ p-value $<0.01$. Right panel: RK13 cells were transfected with vectors expressing ERM and CoAA or AxxQ and protein levels were assessed by immunoblotting as indicated. (B) CoAA increases ERM-dependent transcription of the ICAM-1 promoter. RK13 cells were transfected with the ICAM-1-Luc reporter plasmid and with plasmids bearing the ERM and CoAA or AxxQ genes, $*=$ p-value $<0.01$. (C) U2OS cells were transfected without (ctrl) or with E2F1 and increasing quantity of CoAA (from 20 to 200ng of Flag-CoAA plasmid) together with 5xE2F-Luc reporter plasmid. (D) RK13 cells were transfected with ERM, ER81 or PEA3 with CoAA or AxxQ together with EndoA-Luc reporter, $*=$ p-value $<$ 0.01 .

FIgURE 4. CoAA RRMs are necessary for CoAA-mediated activation of ERM

(A) Left panel: RK13 cells were transfected with ERM and either CoAA, CoAAC, A1NCoAAC, or hnRNPA1 together with the EndoA-Luc reporter plasmid, *=p-value $<0.02$. 
Right panel: expression of myc-tagged CoAA, CoAAC, A1N-CoAAC and hnRNPA1 as used in the left panel; the asterisk denotes a nonspecific band. (B) Left panel: Schematic representation of CoAAC, hnRNP A1, and the fusion protein A1N-CoAAC. YG Domain: glycine- and tyrosine-rich auxiliary domain. Right panel: In vitro-translated $\left[{ }^{35} \mathrm{~S}\right]$ methioninelabeled CoAAC, A1N-CoAAC, or hnRNPA1 was incubated with GST or GST-ERM. 20\% of the in vitro-translated $\left[{ }^{35} \mathrm{~S}\right]$ methionine-labeled protein used is shown as Input.

\section{FIGURE 5. Endogenous CoAA knockdown decreases ERM transcriptional activity}

(A) Protein extracts were prepared from HeLa cells transfected with control siRNA or CoAA siRNA and equal amounts of protein were subjected to immunoblot analysis with specific antibodies as indicated. (B) CoAA siRNA decreases ERM-induced endogenous ICAM-1 transcription: HeLa cells were transfected with control siRNA or CoAA siRNA in the presence or absence of ERM and were used to determine the relative expression levels of ICAM-1 mRNA by quantitative RT-PCR. Results are expressed as ratios of ICAM-1 mRNA to GAPDH mRNA (endogenous control standard). * ${ }^{*}$ p-value $<0.05$.

\section{FIGURE 6. CoAA controls the imigration-enhancing action of PEA3}

(A-B) CoAA increases the migration-enhancing action of PEA3. Cell migration was determined using Boyden transwell chambers in the presence of mitomycin C $(3 \mu \mathrm{g} / \mathrm{ml})$. Twenty four hours after transfection, MCF7 cells transfected without (mock) or with PEA3 and/or CoAA were seeded on 24-well transwell plates. Cells migrating through pores to the bottom surface of the transwell were fixed with $4 \%$ formaldehyde, stained with $0.5 \%$ crystal violet and counted. Representative pictures of the bottom surface are shown in (A). The results presented in (B) are an average of three random microscopic fields from three 
independent experiments. $*=$ p-value $<0.001$. (C-D) Endogenous CoAA knockdown counteracts PEA3-induced migratory activity. Cell migration was performed as in (A-B). Six hours after transfection, MCF7 cells were retransfected with control siRNA (mock) or CoAA siRNA. Representative pictures of the bottom surface are shown in (C). The results presented in (D) are an average of three random microscopic fields from three independent experiments. $*=$ p-value $<0.001$. 
A Biotin B tagged ERM

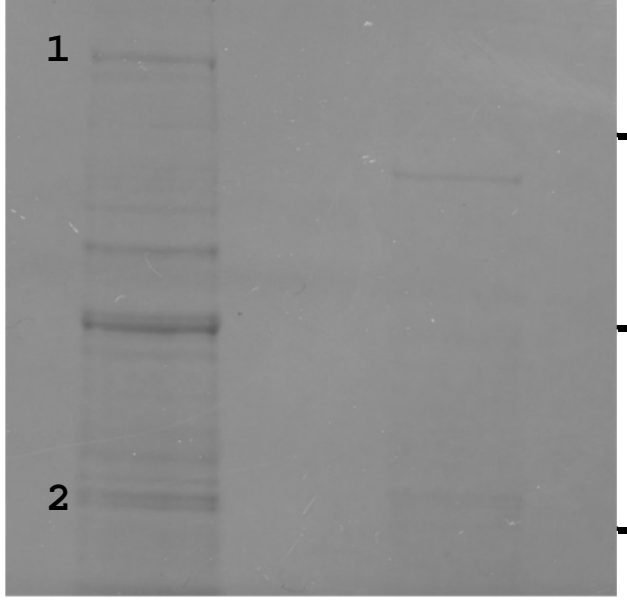

$191 \mathrm{kDa}$

- $97 \mathrm{kDa}$

$64 \mathrm{kDa}$

C

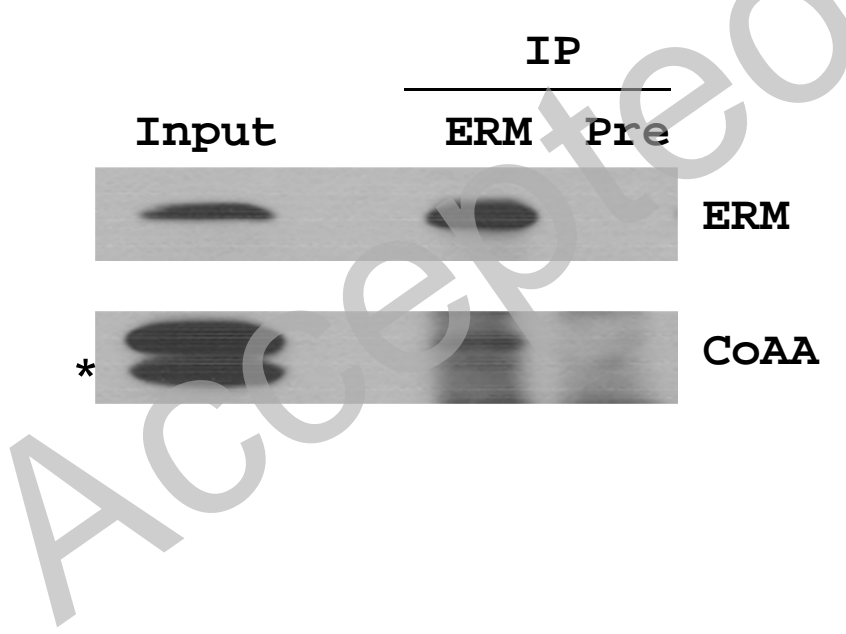

Figure 1

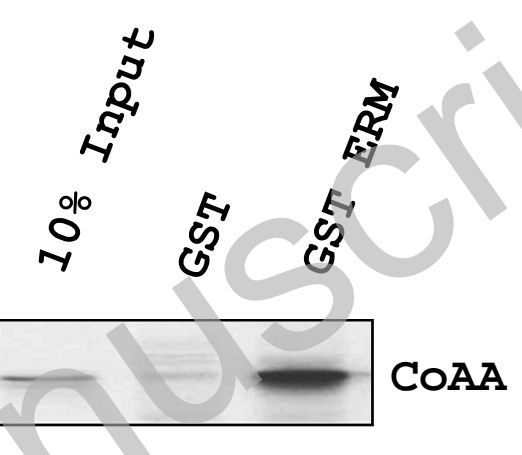

D

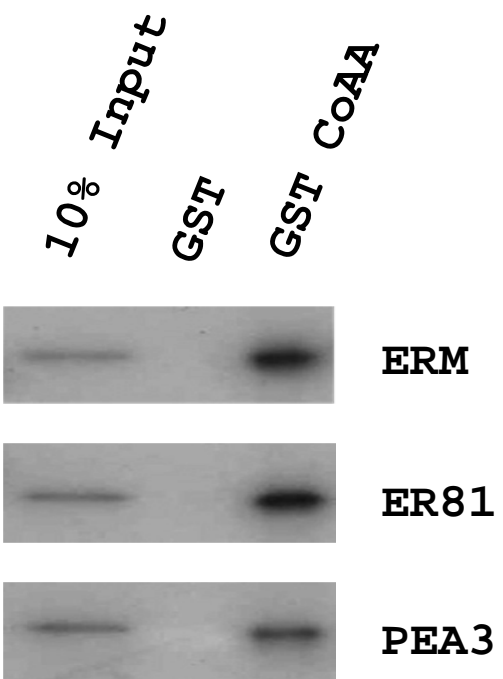


B Biochemical Journal Immediate Publication. Published on 07 Jul 2011 as manuscript BJ20110728

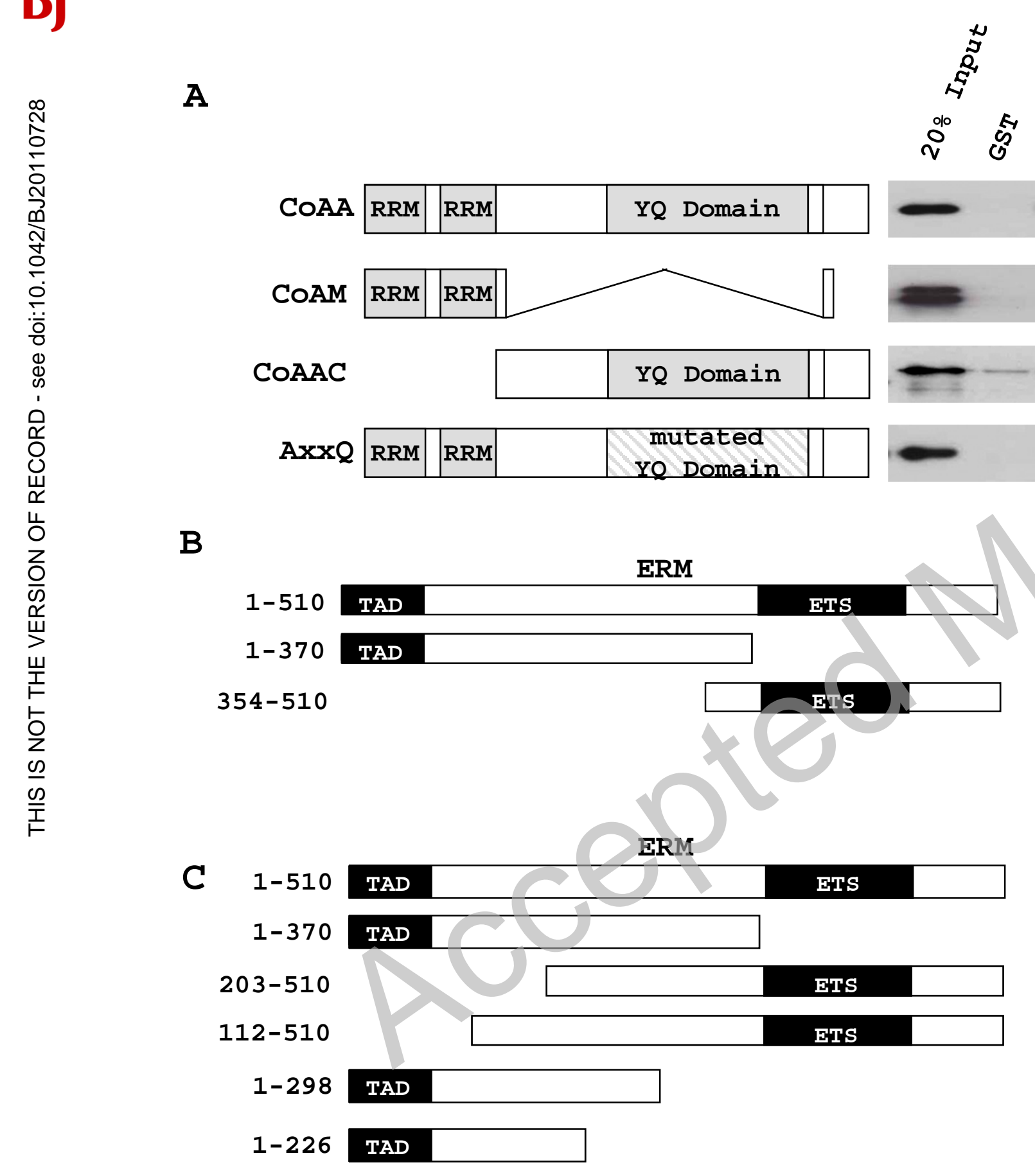

\section{Figure 2}

Licenced copy. Copying is not permitted, except with prior permission and as allowed by law. () 2011 The Authors Journal compilation (๑ 2011 Portland Press Limited 
Figure 3

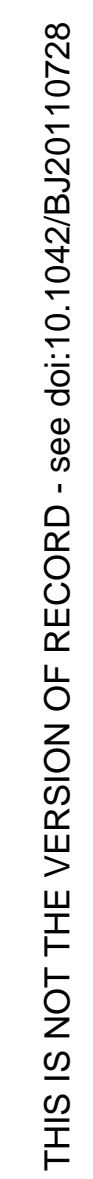
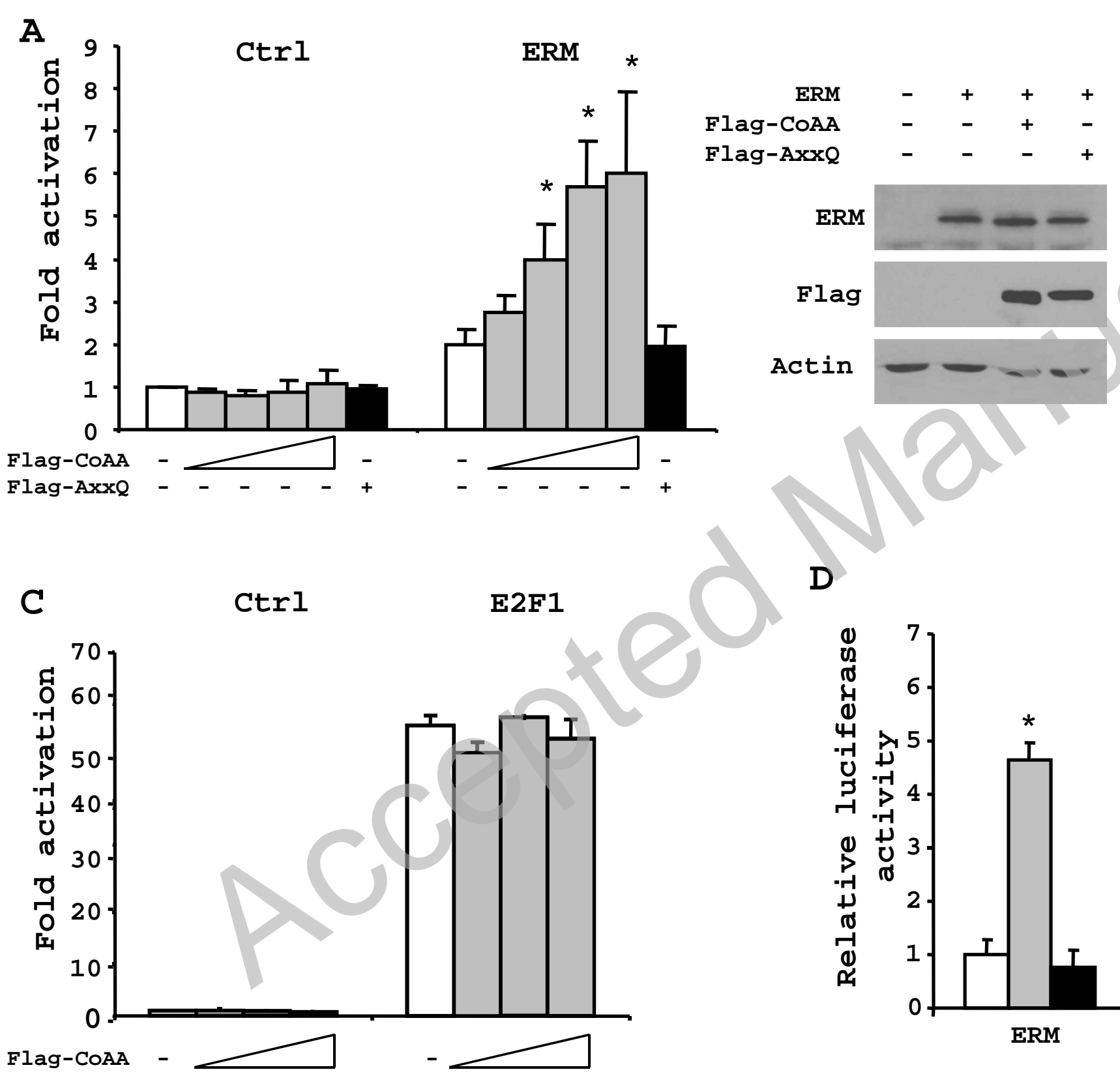

B

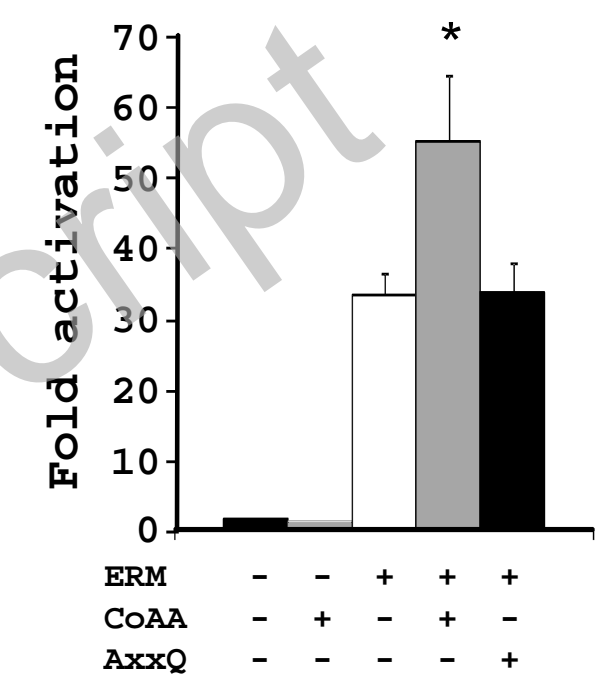

D

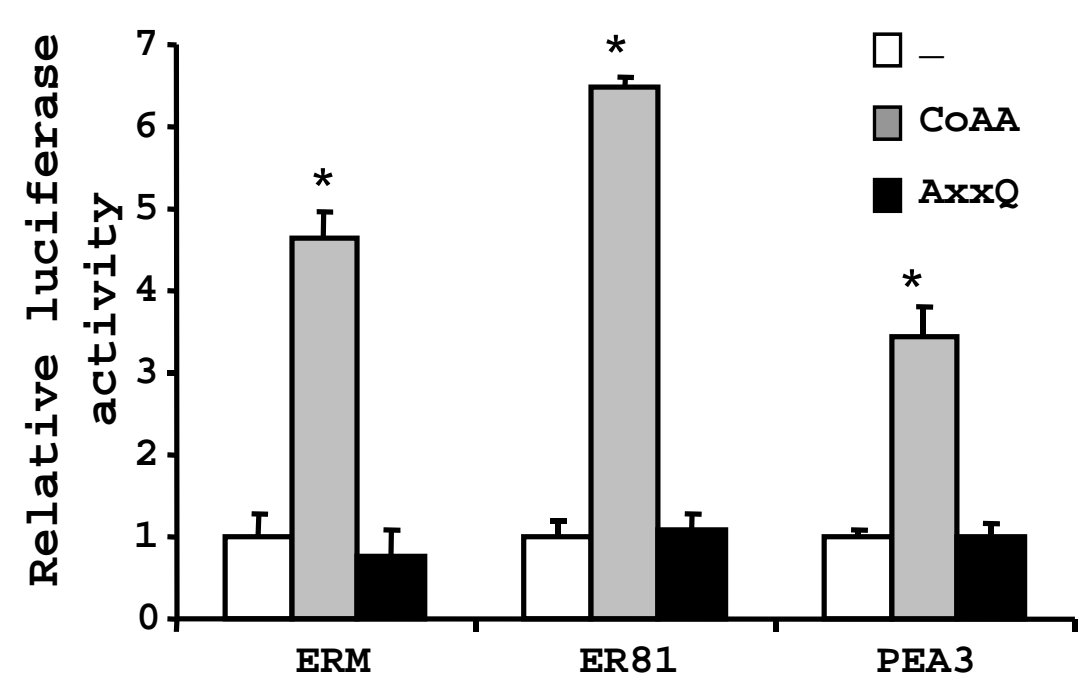

Licenced copy. Copying is not permitted, except with prior permission and as allowed by law. (c) 2011 The Authors Journal compilation @ 2011 Portland Press Limited 


\section{Figure 4}

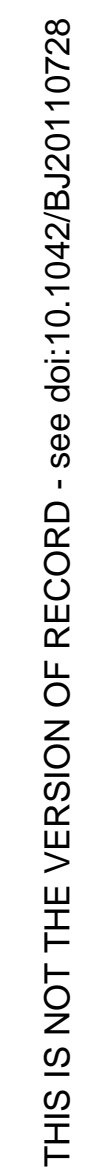

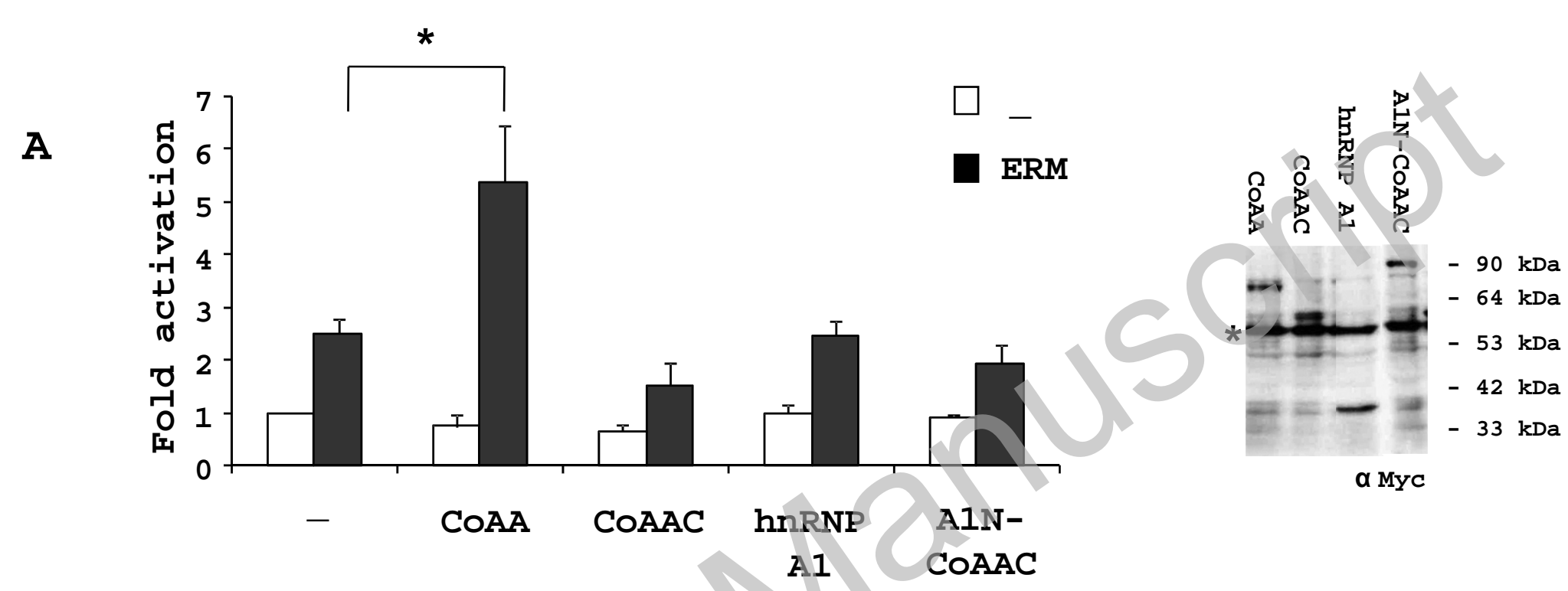

B
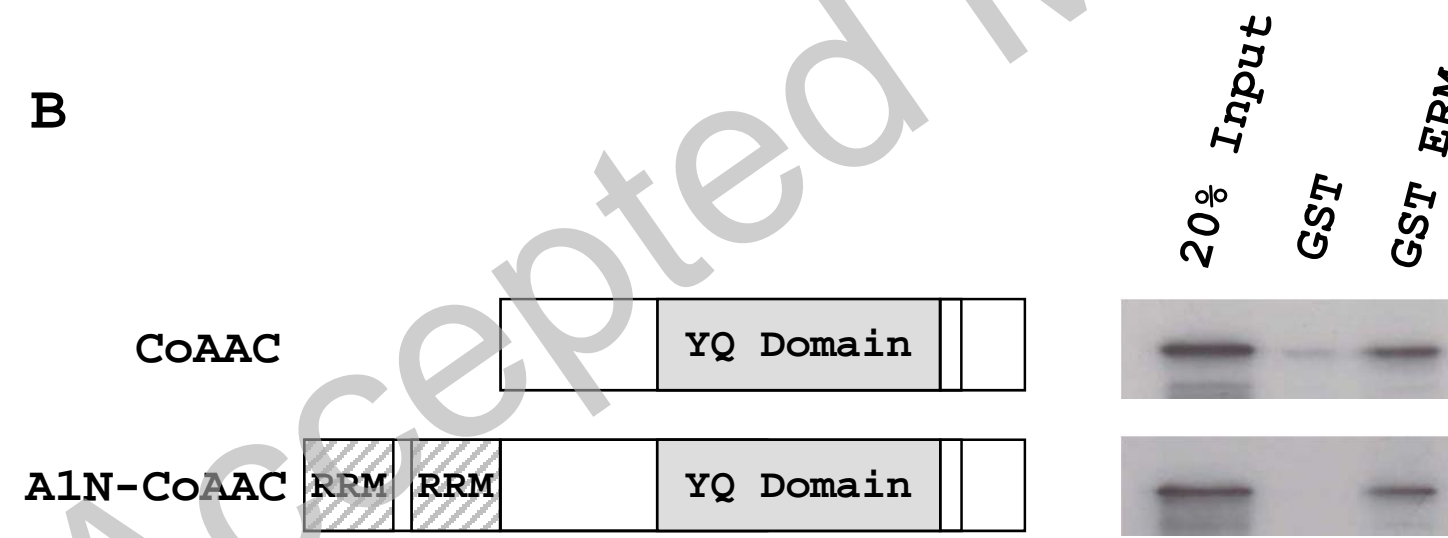

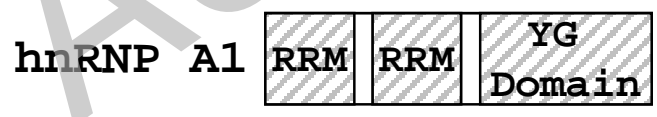


A

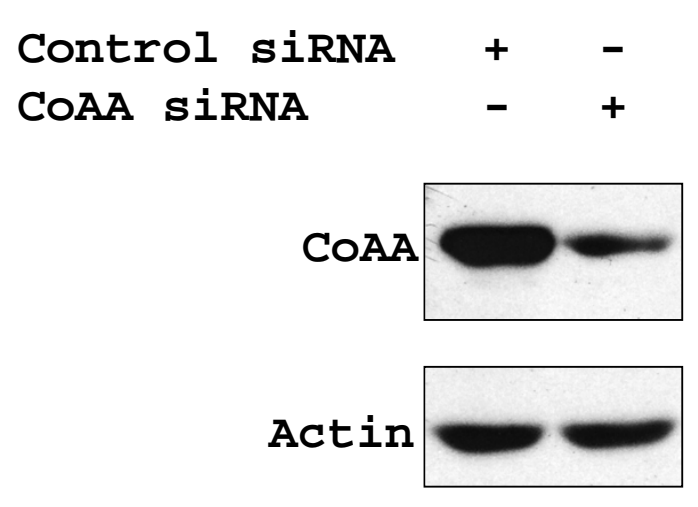

B

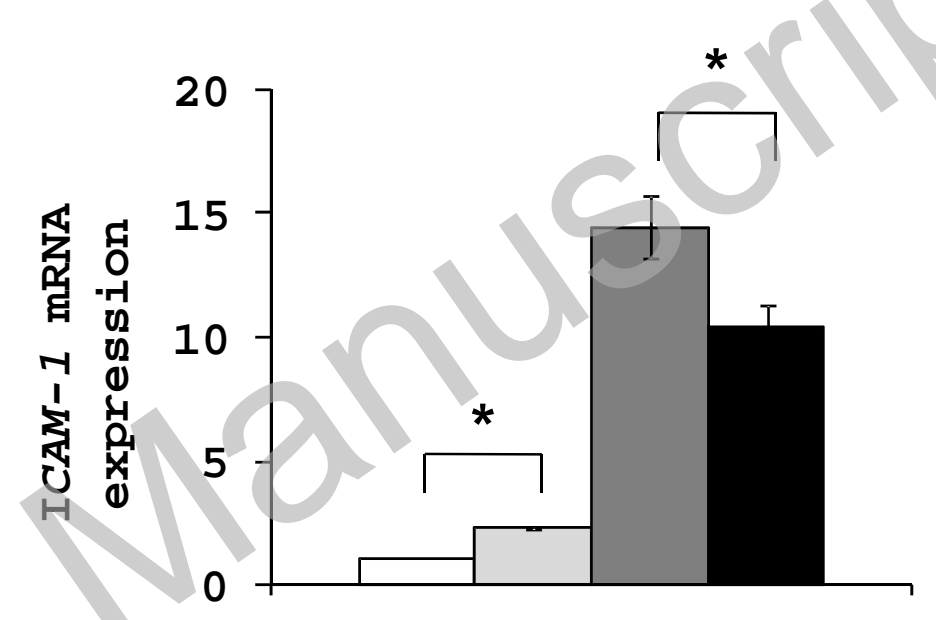


A

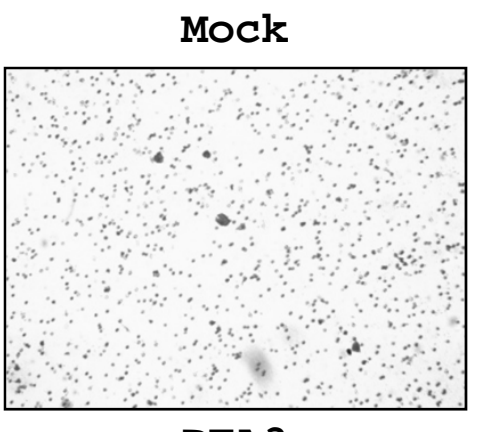

PEA3

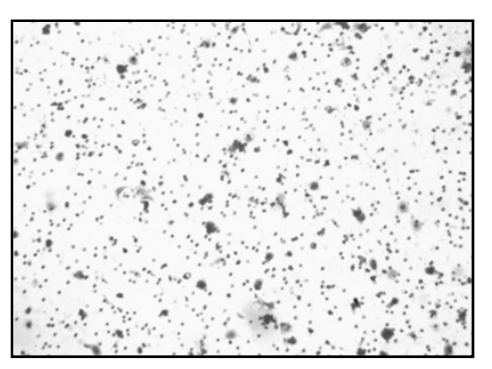

C

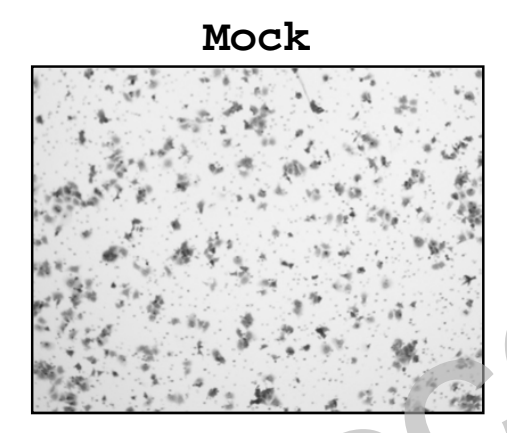

PEA3

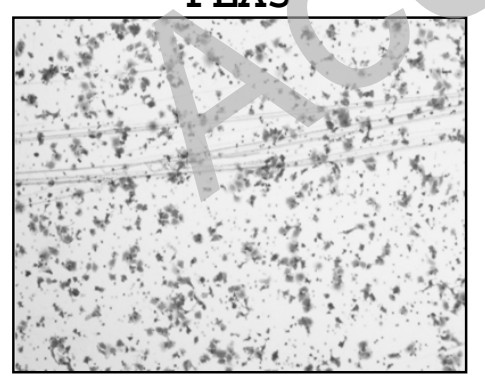

COAA

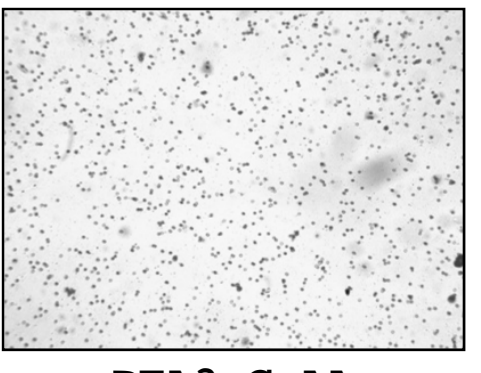

PEA3+COAA

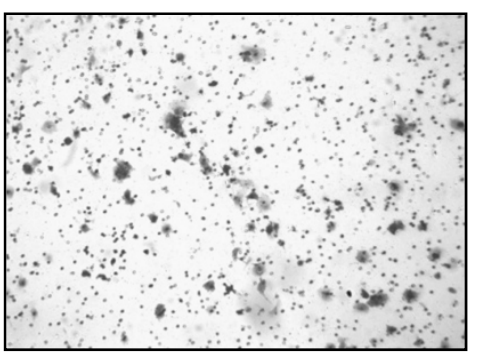

SIRNA COAA

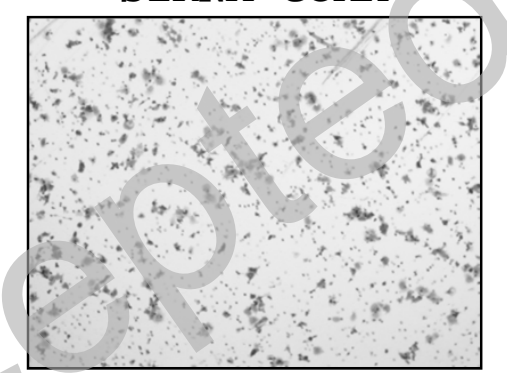

PEA3+siRNA COAA

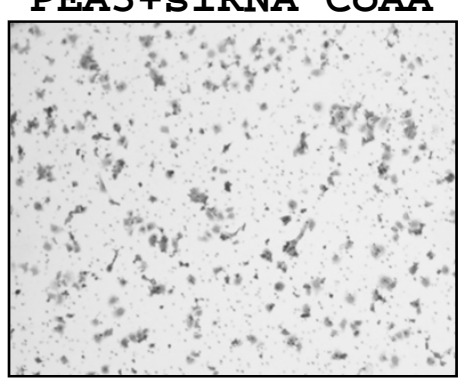

B

Figure 6

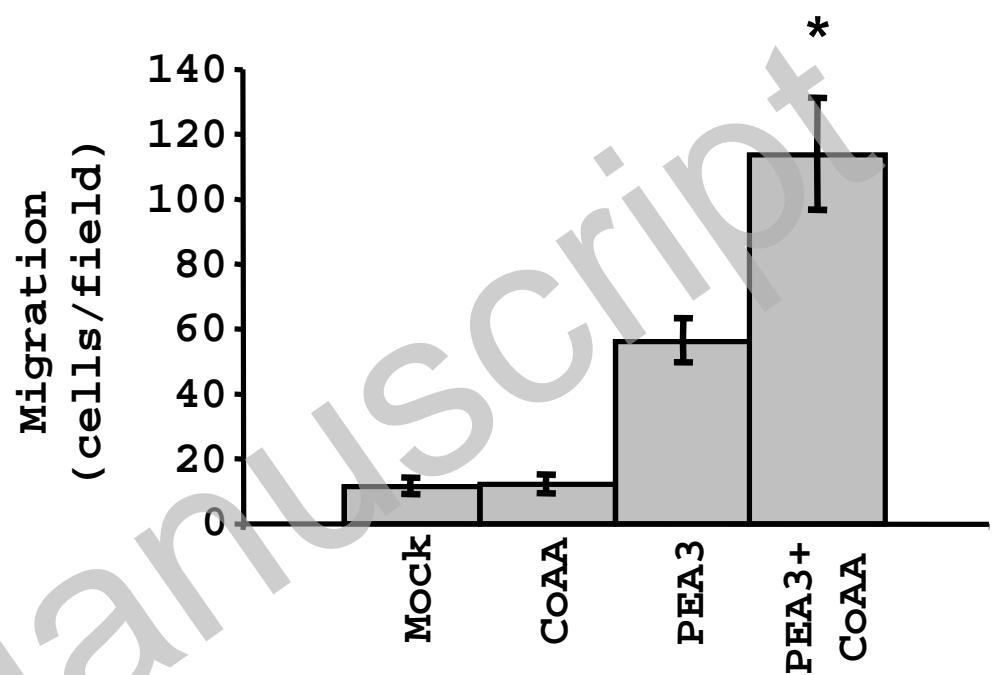

D

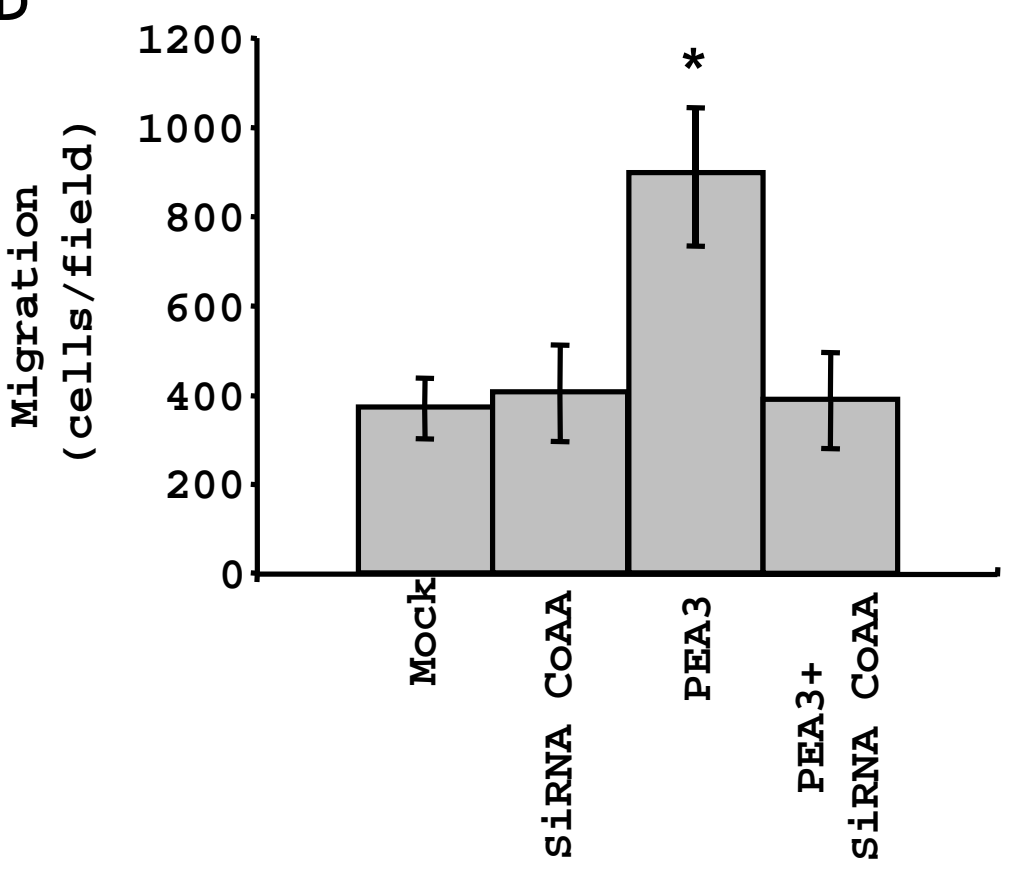

Licenced copy. Copying is not permitted, except with prior permission and as allowed by law. (c) 2011 The Authors Journal compilation @ 2011 Portland Press Limited 